\title{
Compressive Test Characteristics and Constitutive Relationship of Wet Polypropylene Macrofiber-Reinforced Shotcrete
}

\author{
Fenghui Li $\mathbb{D},,^{1,2}$ Yunhai Cheng $\mathbb{D},{ }^{3}$ Fei Wu $\mathbb{D},{ }^{4}$ Chang Su $\mathbb{D},{ }^{5}$ and Gangwei Li $\mathbb{D}^{2,6}$ \\ ${ }^{1}$ State Key Laboratory of Mining-induced Response and Disaster Prevention and Control in Deep Coal Mines, \\ Anhui University of Science and Technology, Huainan 232000, China \\ ${ }^{2}$ School of Mining and Safety Engineering, Anhui University of Science and Technology, Huainan 232000, China \\ ${ }^{3}$ National Engineering Laboratory of Coalmine Backfilling Mining, Shandong University of Science and Technology, \\ Taian 271000, China \\ ${ }^{4}$ College of Resources and Environmental Science, Chongqing University, Chongqing 400030, China \\ ${ }^{5}$ School of Mechanical Engineering, Anhui University of Science and Technology, Huainan 232000, China \\ ${ }^{6}$ Shandong Tianhe Technology Co., Ltd., Zoucheng 273500, China \\ Correspondence should be addressed to Yunhai Cheng; chengyunhai2005@163.com
}

Received 17 November 2020; Revised 8 January 2021; Accepted 23 January 2021; Published 13 February 2021

Academic Editor: Junfei Zhang

Copyright ( $\odot 2021$ Fenghui Li et al. This is an open access article distributed under the Creative Commons Attribution License, which permits unrestricted use, distribution, and reproduction in any medium, provided the original work is properly cited.

\begin{abstract}
Shotcrete is often subject to poor ductility and cracking problems, particularly under high stresses. In order to deal with these issues, the feasibility of adding polypropylene macrofibers to shotcrete was verified. To ascertain the supporting effect, dry shotcrete, wet shotcrete, and wet polypropylene macrofiber-reinforced shotcrete (WPMS) were used as samples. Furthermore, the mechanical response characteristics thereof in uniaxial compression tests were compared and analyzed by acoustic emission (AE) monitoring. The results showed that the three materials were brittle, but the ductility, residual strength, and bearing capacity of polypropylene macrofiber-reinforced shotcrete were significantly enhanced. The energy absorption value of plain shotcrete was higher in the cracking stage, while that of polypropylene macrofiber-reinforced shotcrete was greater in the postpeak stage, which showed that the polypropylene macrofiber-reinforced shotcrete had the characteristics of a high crack-initiation strength and toughness. Besides, the energy release from fiber shotcrete occurred after the peak stress rather than near the peak stress. The average energy absorbed by polypropylene macrofiber-reinforced shotcrete was significantly higher than that in dry shotcrete and wet shotcrete, which implied that polypropylene macrofiber-reinforced shotcrete could mitigate the brittle instability of a shotcrete layer. A constitutive model of damage statistics was established based on the test data. The comparison between the experimental data and the fitting results can reflect the characteristics of the total stress-strain curve of such shotcrete. The results provide a basis for the optimization of polypropylene macrofiber-reinforced shotcrete layers.
\end{abstract}

\section{Introduction}

Shotcrete is a commonly used support and sealing method in geotechnical engineering works such as highway lanes and tunnels. Its stress-induced deformation is mainly divided into three stages: bonding, flexure, and thin shell effects. Concrete bonding, compression resistance, and bending resistance strength are critical to the stability of the shotcrete layer [1].

Dry shotcrete (hereinafter referred to as tidal spray, the conventional rotor-type sprayer cannot perform wet spray placement) has low strength, poor toughness, poor deformation resistance, etc. In addition, it fails to adapt to harsh formation conditions such as fractured substrates and high crustal stresses. Wet shotcrete can overcome the shortcomings of dry shotcrete, but there remain problems such as poor toughness and poor crack resistance [2-4].

An effective way to enhance the mechanical properties of concrete is to add steel fibers as an additional basic material; however, such fibers are easy to corrode in steel-fiber shotcrete. It is a material that is difficult to use, and it cannot be dispersed uniformly. Consequently, it is difficult to use in 
underground geotechnical engineering works under complex, wet conditions. To tackle these problems, polypropylene macrofibers (polypropylene fiber) can be used as a substitute. The incorporation of polypropylene fibers into the concrete matrix can significantly enhance the flexural strength, impact toughness, fatigue properties, postpeak ductility, and durability of concrete [5-8].

A new type of composite materials can be prepared by adding a proper amount of three-dimensionally randomly distributed polypropylene macrofibers to the wet-sprayed concrete, which improves the material properties of the concrete. Compared with the plain concrete, the wet polypropylene macrofiber-reinforced shotcrete (WPMS) has better mechanical properties and better deformation ability [9]. Hence, it can adapt to the harsh engineering geological conditions.

The method of judging material failure by using the characteristics of elastic waves caused by material failure has been applied in mines [10-12]. Its principle is consistent with acoustic emission (AE) analysis. An elastic wave that propagates in a concrete material can be recorded by $\mathrm{AE}$ sensors. By analyzing the $\mathrm{AE}$ signals, the dynamic damage state of the material during uniaxial compression can be inferred. Therefore, AE technology is widely adopted to explore the mechanical properties of concrete materials, such as quantifying the severity of any damage [13, 14], counting cracks [15-17], demarcating their types and sizes [18], acquiring knowledge of the dominant fracture mechanism $[19,20]$, and monitoring damage locations.

There has been much research into the mechanical properties of polypropylene macrofiber-reinforced concrete. For example, Wang et al. [21] analyzed the wavelet energy spectra of AE signals during full stress-strain testing of polypropylene macrofiber-reinforced concrete under different strain rates. Aslan [18] and Dong et al. [22] inferred different damage mechanisms using the amplitude range of recorded AE signals. Trcka et al. [23] discovered that the higher content of polypropylene fibers could inhibit crack opening in lightweight concrete based on AE characteristic parameters. Yu et al. [24] found that the cumulative count of $\mathrm{AE}$ ringing during split tensile failure increased, and the relationship between them was quasilinear with increasing content of polypropylene fibers.

$\mathrm{AE}$ position detection and other indoor testing methods were adopted to investigate the mechanical response characteristics and constitutive relationship governing the uniaxial compression testing of WPMS, providing reference for the optimization of such support schemes.

\section{Experimental Program}

2.1. Experimental Materials and Preparation of Specimens. The dry shotcrete, wet shotcrete, and WPMS slabs required for the test were taken from a project site. The raw materials were as follows: cement (grade 42.5) and medium coarse sand with a fineness modulus greater than 2.5 , with the particle size of the stone being $5-12 \mathrm{~mm}$, and the proportions of cement, sand, and stone are listed in Table 1. The dry spray quicksetting accelerator was an ordinary powdered aluminate quick-setting accelerator, and the wet spray accelerator was an alkali-free liquid accelerator. Water-reducing admixture was added for the wet spray method, to $0.8 \%$ of the mass of cement, which was conducive to enhancing the strength of the shotcrete; the water-cement ratio was 0.5 , and polypropylene macrofibers $\left(1 \mathrm{~kg} / \mathrm{m}^{3}\right)$ were added to the wet-sprayed concrete to make WPMS (Figure 1 and Table 1) [25].

The length of the chosen polypropylene macrofibers is $48 \mathrm{~mm}$; the shape of each polypropylene macrofibers is wave-like, with a stelliform cross-section. The toughness of 5 to $8 \mathrm{~kg}$ of polypropylene fiber is equivalent to that of $50 \mathrm{~kg}$ of steel fiber. The number of fibers per kilogram is between 44,000 and 78,000 . The tensile strength of the polypropylene macrofibers is $530 \mathrm{MPa}$, and their modulus of elasticity modulus is $7 \mathrm{GPa}$ (Table 2).

According to Technical Code for Engineering of Ground Anchorages and Shotcrete Support (GB50086-2001) and the Technical Specification for Geotechnical Anchoring and Shotcrete Support Engineering (GB50086-2011), on-site spraying was undertaken and maintenance dimensions were concrete slabs measuring $500 \mathrm{~mm} \times 500 \mathrm{~mm} \times 100 \mathrm{~mm}$ (length $\times$ width $\times$ height). The core method was utilized to prepare standard specimens measuring $50 \mathrm{~mm} \times 100 \mathrm{~mm}, 10$ specimens of each kind of concrete were acquired, and six standard specimens were chosen therefrom for testing (dry shotcrete test specimen nos. G1-G6, wet shotcrete test specimen nos. S1-S6, and WPMS test specimen nos. X1-X6).

2.2. Loading Device and Test Method. A load control system and an AE monitoring system were used in the test. The mechanical loading was applied using an RMT rock mechanics testing machine, which could record parameters such as load and vertical deformation and output the original data. The AE monitoring system could automatically collect and store various $\mathrm{AE}$ parameters. The $\mathrm{AE}$ signals were acquired by eight sensors fixed on the surface of the test specimen (Figure 2) [25]. The main ruptured zone of the test specimens was located between the eight sensors, which could realize real-time monitoring and three-dimensional positioning of the $\mathrm{AE}$ signals.

To validate the $\mathrm{AE}$ test effect, the $\mathrm{AE}$ sensor was adhered to the surface of the test specimens and fixed with a rubber band (Vaseline ${ }^{\mathrm{TM}}$ was used as the couplant). Before the test, a pencil core was used as an analog source in a simulation test, which could check the response of the AE detection system to an external signal source and eliminate the external interference (noise). The test was started after the debugging. During the test, the uniaxial loading test and the AE test were undertaken simultaneously, and the loading system was employed to apply axial displacement control at a rate of $2 \times 10^{-6} \mathrm{~m} / \mathrm{s}$. The loading system automatically recorded the mechanical test process parameters, and the $\mathrm{AE}$ instrument software collected the $\mathrm{AE}$ raw data by processing the signals received by the eight sensors. 
TABLE 1: Mix proportions of shotcrete (mass ratio).

\begin{tabular}{lcccccc}
\hline Material & Cement & Sand & Stone & $\mathrm{S}_{1}$ & $\mathrm{~S}_{2}$ & Fiber \\
\hline Dry shotcrete & 1 & 2 & 2 & 0.035 & & \\
Wet shotcrete & 1 & 2 & 1.75 & & 0.06 & \\
Wet PP shotcrete & 1 & 2 & 1.75 & & 0.06 & 1 \\
\hline
\end{tabular}

Remark $\mathrm{S}_{1}$ : powdered aluminate accelerator; $\mathrm{S}_{2}$ : alkali-free liquid accelerator; water-reducing admixture $0.8 \%$ (cement weight)

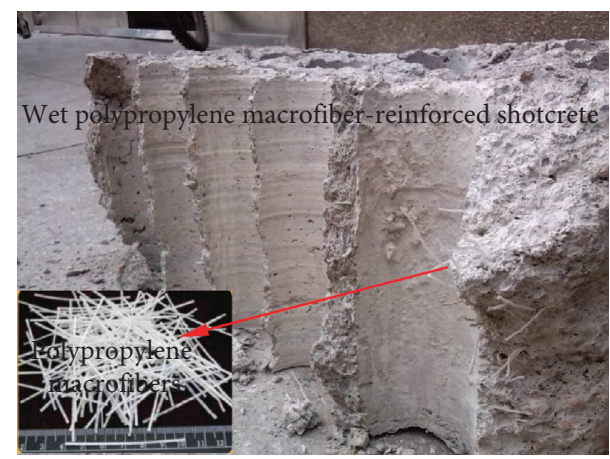

FIGURE 1: Appearance of polypropylene macrofibers and drilling of a wet shotcrete specimen.

Table 2: Properties of polypropylene macrofibers.

\begin{tabular}{lc}
\hline Property of materials & Performance description \\
\hline Length & $48 \mathrm{~mm}$ \\
Shape structure & Wave type, star cross- \\
Equivalent toughness 0f $50 \mathrm{~kg}$ of steel & $5-8 \mathrm{~kg}$ \\
fiber & $44000-78000$ \\
The number of fibers per kilogram & $530 \mathrm{MPa}$ \\
Tensile strength & $7 \mathrm{GPa}$ \\
Modulus of elasticity & \\
\hline
\end{tabular}

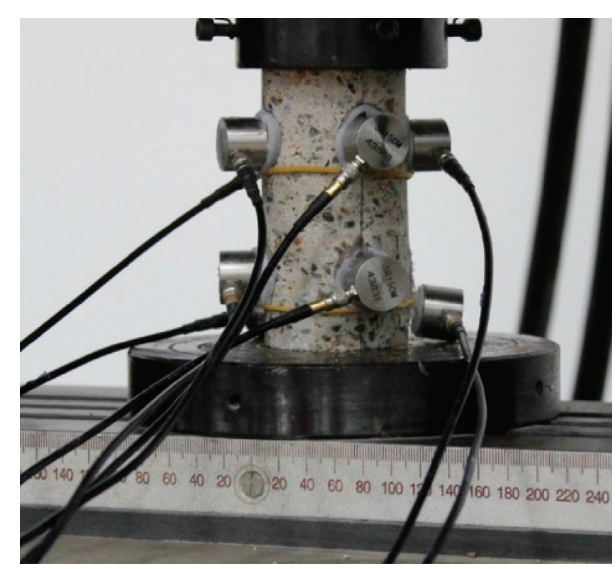

Figure 2: Loading device and arrangement of AE sensors.

\section{Test Results and Characteristics}

3.1. Compressive Stress-Strain Relationship and Characteristics of Specimens. The stress-strain relationship of three kinds of concrete under uniaxial compression is illustrated (Figure 3). Before the peak stress is reached, the rate of

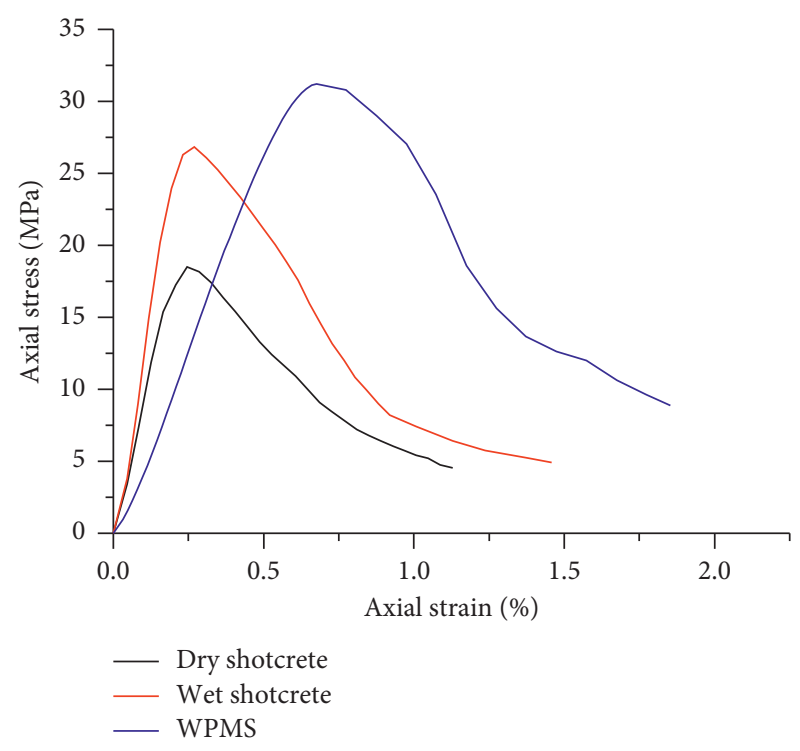

FIGURE 3: Stress-strain relationships for three different shotcrete mixes subject to uniaxial compression.

change of the stress in dry and wet shotcrete is higher than that in the WPMS under unit strain. When the peak stress is reached, the peak strains of dry shotcrete, wet shotcrete, and WPMS are $0.245 \%, 0.270 \%$, and $0.676 \%$. The peak strain in the WPMS is 1.76 times and 1.50 times than that in the dry shotcrete and wet shotcrete, respectively. This implies that, when the test specimen is broken, the WPMS concrete is less deformed and that the plasticity of the WPMS exceeds that of the dry and wet shotcrete mixes. It is still a brittle material, despite the addition of the polypropylene macrofibers, but its ductility is significantly enhanced [26].

The peak stresses of dry shotcrete, wet shotcrete, and WPMS are 18.52 MPa, 26.82 MPa, and 31.21 MPa. The uniaxial compressive strength of wet shotcrete is $30.95 \%$ higher than that of dry shotcrete. There is no significant change in strain at time of failure. The uniaxial compressive strength and the strain at the onset of damage to the WPMS show a significant increase compared with those of wet shotcrete. Moreover, the compressive strength is increased by $14.1 \%$, and the peak strain is increased by $125 \%$. This shows that the wet shotcrete only enhances the strength while the ability to adapt to the roadway deformation of the WPMS is greatly improved. The initial strength attenuation coefficients of three different shotcrete mixes are displayed in Table 3.

The initial strength attenuation coefficients [27, 28] of dry shotcrete, wet shotcrete, and WPMS are 0.803, 0.743, and 0.667 . The initial strength attenuation coefficient of WPMS is small, indicating its relative ductility. The WPMS can still bear load after the onset of damage and provides a certain residual support, which helps to prevent the spray layer from falling.

The stress-strain curve indicates the basic mechanical properties of the three specimens and shows the strength and ductility of the specimens and the energy absorbed in the specimens. As the energy absorbed by the specimen 
TABLE 3: Initial strength attenuation coefficients of three different shotcrete mixes.

\begin{tabular}{lccc}
\hline Specimen code & Dry shotcrete & Wet shotcrete & Wet polypropylene macrofiber shotcrete \\
\hline 1 & 0.860 & 0.719 & 0.877 \\
2 & 0.723 & 0.665 & 0.571 \\
3 & 0.672 & 0.799 & 0.696 \\
4 & 0.805 & 0.757 & 0.650 \\
5 & 0.850 & 0.836 & 0.551 \\
6 & 0.909 & 0.682 & 0.658 \\
Average & 0.803 & 0.743 & 0.667 \\
\hline
\end{tabular}

cannot be obtained from the stress-strain curve alone, the energy absorption of each test specimen was also studied (Table 4). The energy absorption was determined by integrating stress-induced changes to obtain the area under the stress-strain curve.

The average energy absorbed by wet shotcrete is almost the same as that of dry shotcrete (at 0.07 times that of dry shotcrete). The average energy absorbed by WPMS is 1.53 times that of wet shotcrete. The main reason for this is that the mechanical properties of the new material formed by adding polypropylene macrofibers to the wet shotcrete are different from those of the wet shotcrete, whose compressive strength and strain at the stress peak increase.

For the dry shotcrete, compared with the wet shotcrete, the energy absorbed by dry shotcrete is always less than that absorbed by wet shotcrete (Figure 4). Therefore, the energy absorption of the concrete after the spraying process increases from the dry spraying process to the wet spraying process: the energy absorbed by the wet shotcrete in the cracking stage is high and that in WPMS in the postpeak stage is also high. Moreover, the effects of the polypropylene macrofibers increase with increasing strain in the material.

3.2. AE Monitoring and Characterization. The number of impacts and energy are two important AE parameters that reflect the activity and intensity of the AE signal. AE energy is a parameter that characterizes the strength of the signal source; the number of impacts is the number of $\mathrm{AE}$ signals detected on one channel of the AE, and it is used to assess $\mathrm{AE}$ activity. The AE fracture distribution can accurately reflect the space-time evolution process of the rupture position of the test specimen [29]. According to the stage change of $\mathrm{AE}$ energy and the number of impacts, the AE fracture distribution image of the typical test specimens at the moment of such a change was selected. It is then combined with $\mathrm{AE}$ energy and the number of impacts to investigate the fracture and destruction of specimens.

3.2.1. Dry Shotcrete. According to the changing stages of AE energy and the number of impacts in dry shotcrete specimens, typical samples of dry shotcrete were divided into three stages: 0-60 s (Stage I), 60-200 s (Stage II), 200 s-end (Stage III). The energy, the number of AE impacts, stresses, crack distribution, and time were coupled to reveal the fourparameter-time relationship (Figure 5).

The dry shotcrete test has energy release from the beginning to the peak stress within 200 s. The energy release is sparse in the early stage of the test, but dense near the peak stress. Several large energy releases are generated near the peak stress, up to $82.85 \mathrm{mV} \cdot \mathrm{ms}$. The number of AE impacts increases at any time within $200 \mathrm{~s}$ from the beginning to reaching the peak stress. The number of impacts in Stage I increases slowly, then rapidly in Stage II, and stably in Stage III. There are few ruptures in Stage I and a large number of scattered ruptures in Stage II. At the end of Stage III, the rupture distribution is similar to that in Stage II. The rupture data are in good agreement with the AE energy and the number of impacts.

3.2.2. Wet Shotcrete. According to the changing stages of AE energy and impact number of wet shotcretes, the typical specimens of wet shotcrete were divided into three stages: 0-140 s (Stage I), 140-330 s (Stage II), and 330 s-end (Stage III). The AE energy, the number of AE impacts, stresses, fracture distribution, and time were coupled to acquire the four-parameter-time relationship diagram (Figure 6).

The AE energy release was observed within $200 \mathrm{~s}$ from the start of the test to reaching the peak stress. From 0 to $340 \mathrm{~s}$, the energy release is uniform with a small decrease at around $100 \mathrm{~s}$. After $340 \mathrm{~s}$, the energy release distribution is abnormally sparse. A large energy release occurs near the peak stress, and the released energy reaches $244.15 \mathrm{mV} \cdot \mathrm{ms}$. The wet shotcrete specimens generate a small amount of cracking in Stage I and many concentrated cracks in Stage II. At the end of Stage III, the crack distribution is akin to that in Stage II, which is in good agreement with the energy and impact data. The number of impacts increases at any time within $200 \mathrm{~s}$ from the beginning to reaching the peak stress. The number of impacts increases slowly in Stage I, rapidly in Stage II, and stably in Stage III.

3.2.3. WPMS. The changing stages of AE energy and the number of impacts in WPMS are different from those of plain concrete: it showed a stable period, so the WPMS specimens were selected between 0 and $10 \mathrm{~s}$ (Stage I), 10-410 s (Stage II), 410-560 s (Stage III), and 560 s to the end of trial (Stage IV). The AE energy, the number of AE impacts, stresses, fracture distribution, and time were coupled to obtain the four-parameter-time relationship diagram (Figure 7).

The energy absorbed by WPMS occurs mostly in Stages I and III and only marginally in Stages II and IV. There are several large energy release events in Stage III, reaching $177.56 \mathrm{mV} \cdot \mathrm{ms}$. Different from dry and wet shotcrete, a large 
TABLE 4: Energy absorption at time of failure for three different shotcrete mixes (MPa).

\begin{tabular}{lccc}
\hline Specimen code & Dry shotcrete & Wet shotcrete & Wet polypropylene macrofiber shotcrete \\
\hline 1 & 8.381 & 10.677 & 21.946 \\
2 & 6.617 & 7.078 & 19.153 \\
3 & 7.453 & 7.346 & 20.472 \\
4 & 7.922 & 8.081 & 23.867 \\
5 & 5.155 & 6.529 & 17.875 \\
6 & 8.920 & 7.946 & 17.336 \\
Average & 7.408 & 7.943 & 20.108 \\
\hline
\end{tabular}

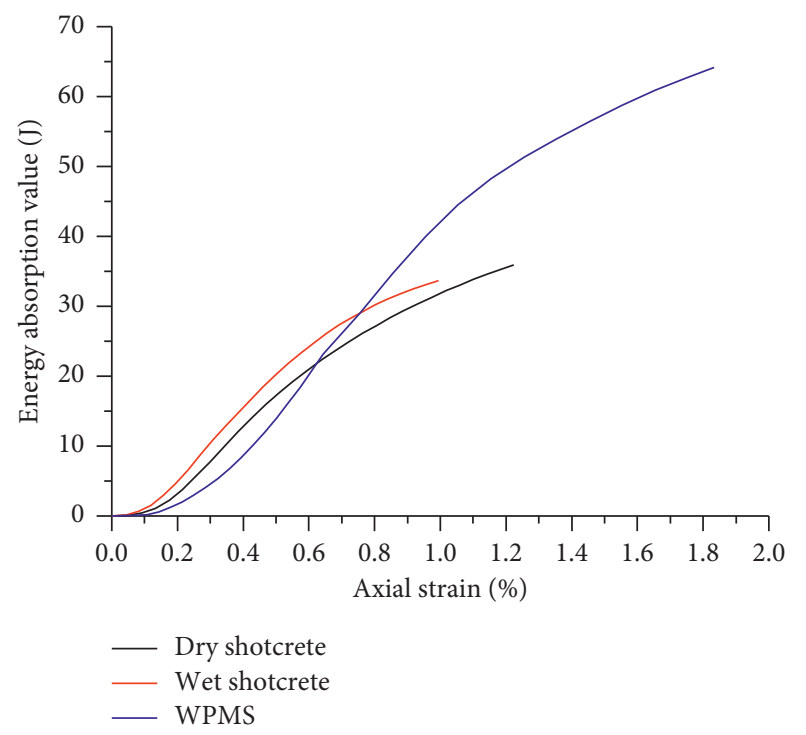

Figure 4: Energy absorption (v). Axial strain in three different shotcrete mixes.

amount of energy released from the WPMS appears after, rather than at the peak stress.

The number of AE impacts of wet imitation-steel-fiber shotcrete does not always increase: in Stage I, it rises rapidly. When the number of impacts reaches 30 , a stable period of $400 \mathrm{~s}$ follows which matches the concomitant stress increase. The number of impacts in Stage III increases rapidly and then decelerates in Stage IV.

A small amount of rupturing occurs at the end of Stage I. The fracture distribution is similar to that of the end of Stage I. Many uniformly distributed ruptures occur during Stages III and IV (the distribution of the fracture points therein is uniform). The fracture data are in good agreement with the AE energy and the number of impacts.

3.2.4. AE Characteristics of Three Shotcrete Mixes. The AE signals from the three different types of concrete can be roughly divided into three stages: a smooth failure stage, severe damage stage, and later damage stage; all of which have a distinct rapid growth period, during which the concrete is destroyed, and energy is released rapidly.

The AE signals from the three different types of concrete show the following differences:

(1) The AE signal of the WPMS has a significant turning point before the severe failure stage while the $\mathrm{AE}$

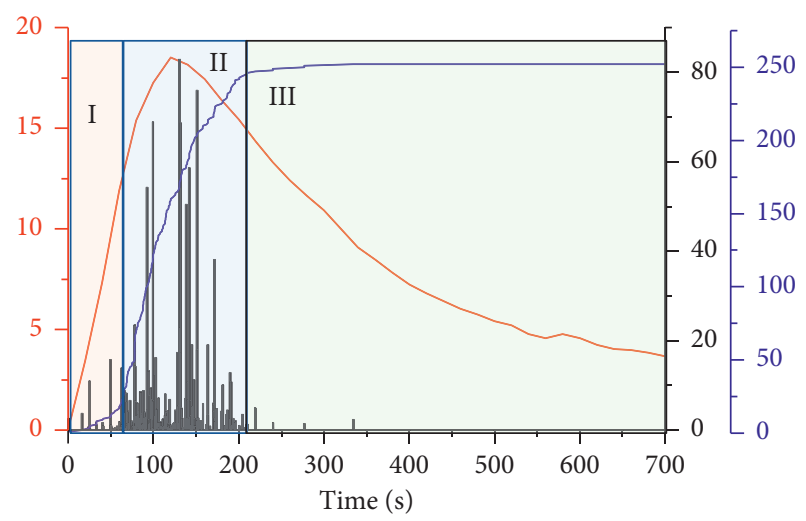

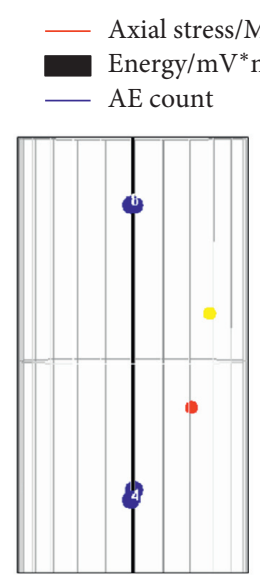

(I)

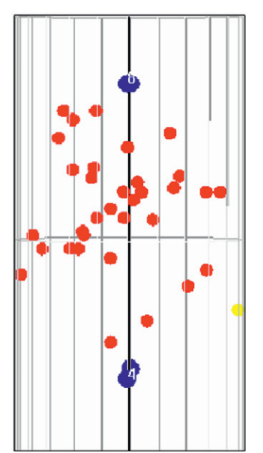

(II)

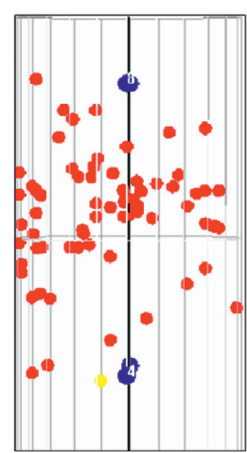

(III)
FIGURE 5: The four-parameter-time relationship for dry shotcrete.

signal of the ordinary shotcrete appears more uniform before the onset of severe destruction

(2) Compared with ordinary shotcrete, the severe failure stage of WPMS is delayed until reaching the peak stress

(3) The distribution of the fracture points of the WPMS is more uniform than that of ordinary shotcrete, which is conducive to improvement of the bearing capacity

\section{Shotcrete Damage Analysis}

4.1. The Statistical Damage Constitutive Model. To demonstrate the differences of different kinds of concrete constitutive relations, its damage performance was analyzed. The 


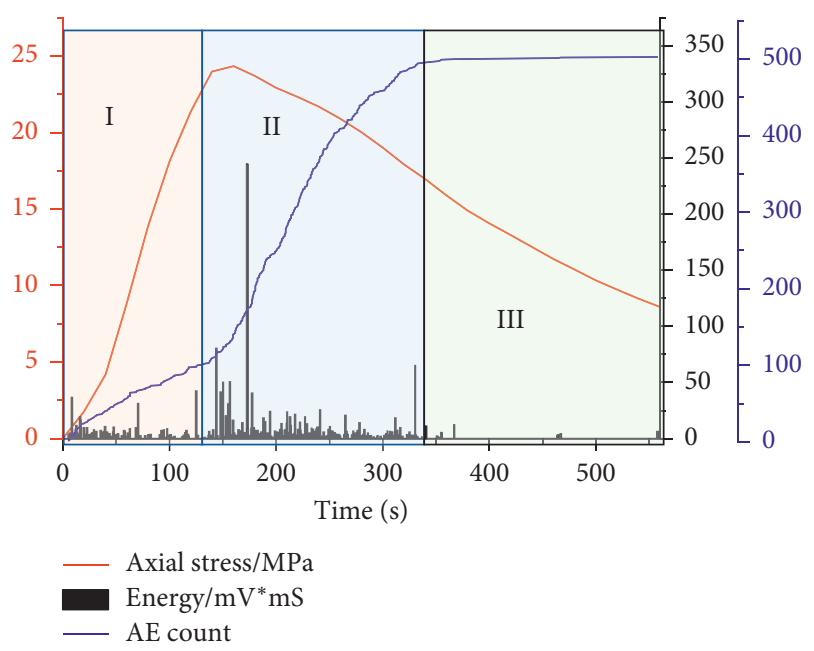

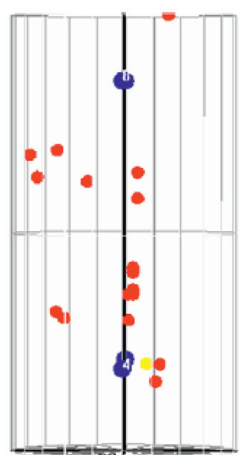

(I)

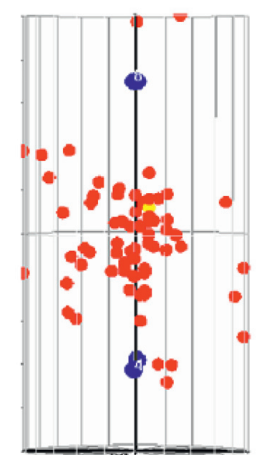

(II)

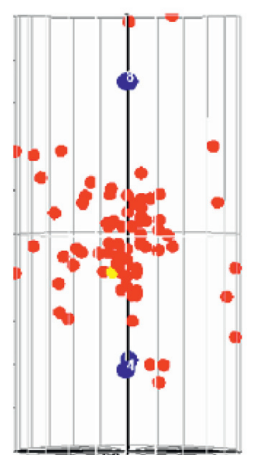

(III)
FIGURE 6: The four-parameter-time relationship for wet shotcrete.
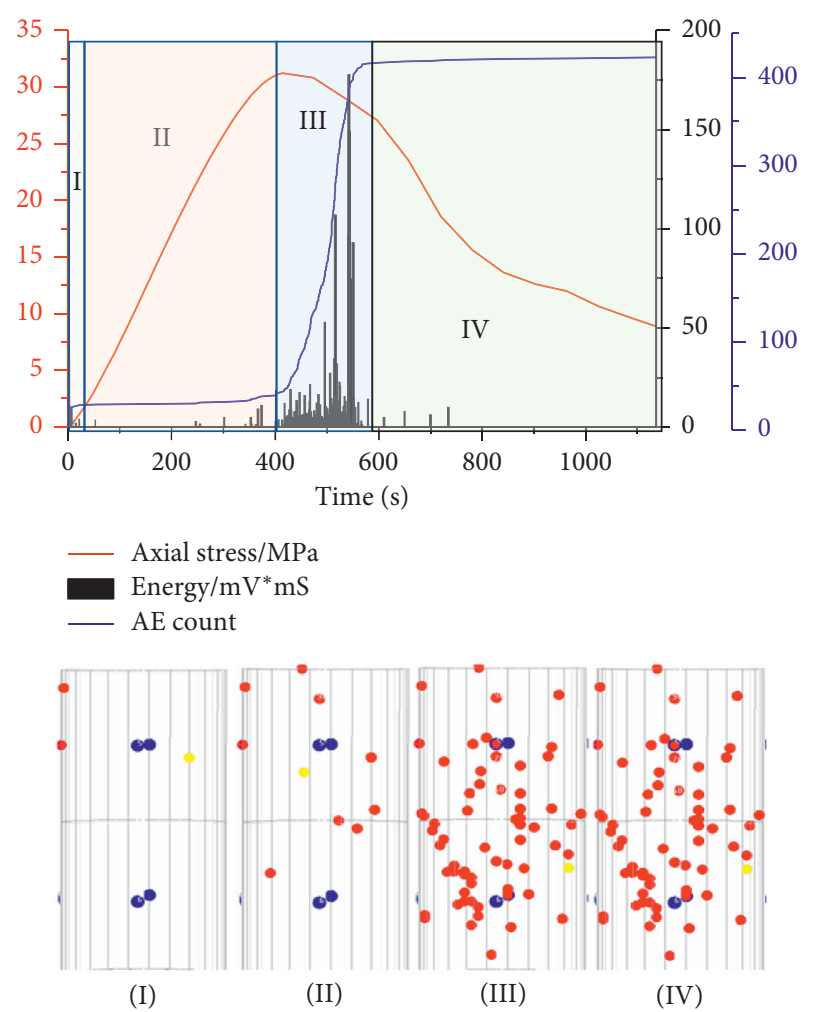

FIGURE 7: Four-parameter-time relationship for WPMS. statistical damage constitutive model of different concretes was established. The parameters of the statistical damage constitutive model were compared to provide reference for engineering applications.

It is known that the strength of rock and concrete materials can be described by statistical distribution and it obeys the Weibull distribution with probability density function [30-33]:

$$
P(\varepsilon)=\frac{m}{F}\left(\frac{\varepsilon}{F}\right)^{m-1} \exp \left[-\left(\frac{\varepsilon}{F}\right)^{m}\right]
$$

where $\varepsilon$ is the strain and $m$ and $F$ are material parameters.

If the total number of microelements is $N$, then the number $c$ of damaged microelements under a certain strain is

$$
\begin{aligned}
c(\varepsilon) & =\int_{0}^{\varepsilon} \mathrm{NP}(x) \mathrm{d} x, \\
& =N\left\{1-\exp \left[-\left(\frac{\varepsilon}{F}\right)^{m}\right]\right\} .
\end{aligned}
$$

Damage variable $D$ is the ratio of the number of broken microelements $c$, to the total number of microbodies $N$, so

$$
\begin{aligned}
D & =\frac{c}{N}, \\
& =1-\exp \left[-\left(\frac{\varepsilon}{F}\right)^{m}\right] .
\end{aligned}
$$

Equation (3) is the damage evolution equation of the concrete under load.

According to the theory of continuous damage mechanics, if the damaged part of concrete has no bearing capacity, its constitutive equation is

$$
\sigma=E \varepsilon(1-D)
$$

Equation (4) is applicable when concrete is under tension, but the concrete can still bear load (even under compression); hence, damage coefficient $\delta$ is introduced under the pressure condition, so the constitutive equation is

$$
\sigma=E \mathcal{E}(1-\delta D) .
$$

Substituting equation (3) into equation (5), we obtain

$$
\sigma=E \varepsilon(1-\delta)+\delta \exp \left[-\left(\frac{\varepsilon}{F}\right)^{m}\right]
$$

Equation (6) elucidates the unified statistical damage constitutive model of concrete under uniaxial compression.

4.2. Verification of the Statistical Damage Constitutive Model. Based on the experimental data pertaining to the three different concrete mixes, the parameters of the statistical damage constitutive model were determined by using the nonlinear least squares method (Table 5). The comparison between the theoretical fitting results and the experimental data is shown in Figure 8. 
TABLE 5: Parameters pertaining to the statistical damage constitutive model.

\begin{tabular}{|c|c|c|c|c|}
\hline \multirow{2}{*}{ Model } & \multicolumn{4}{|c|}{ Parameter } \\
\hline & $E / \mathrm{GPa}$ & $\delta$ & $F$ & $m$ \\
\hline Dry shotcrete & 11.823 & 0.9646 & 0.0037 & 1.4982 \\
\hline Wet shotcrete & 15.174 & 0.9682 & 0.0042 & 1.6079 \\
\hline Wet polypropylene macrofiber shotcrete & 5.4348 & 0.8909 & 0.0105 & 3.6671 \\
\hline
\end{tabular}

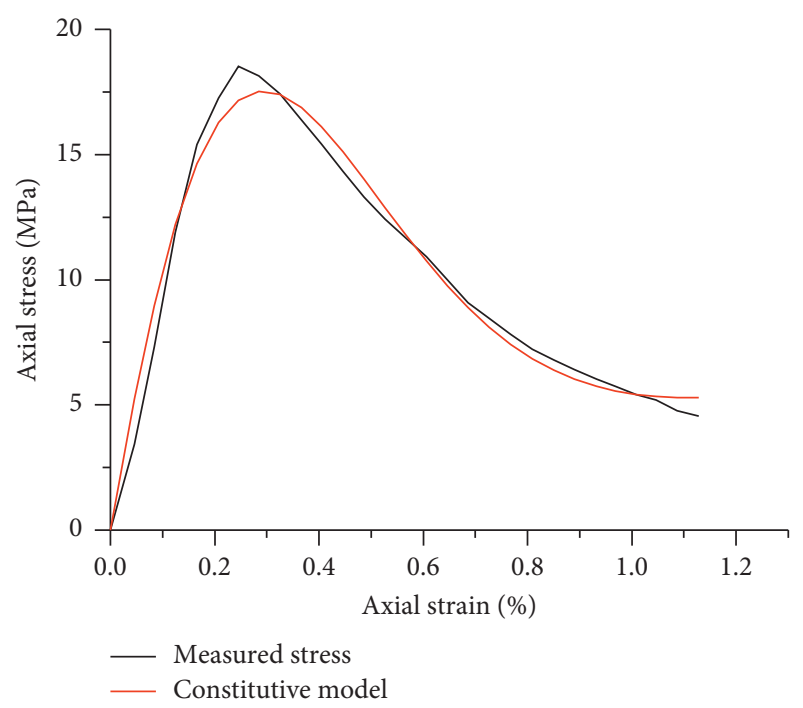

(a)

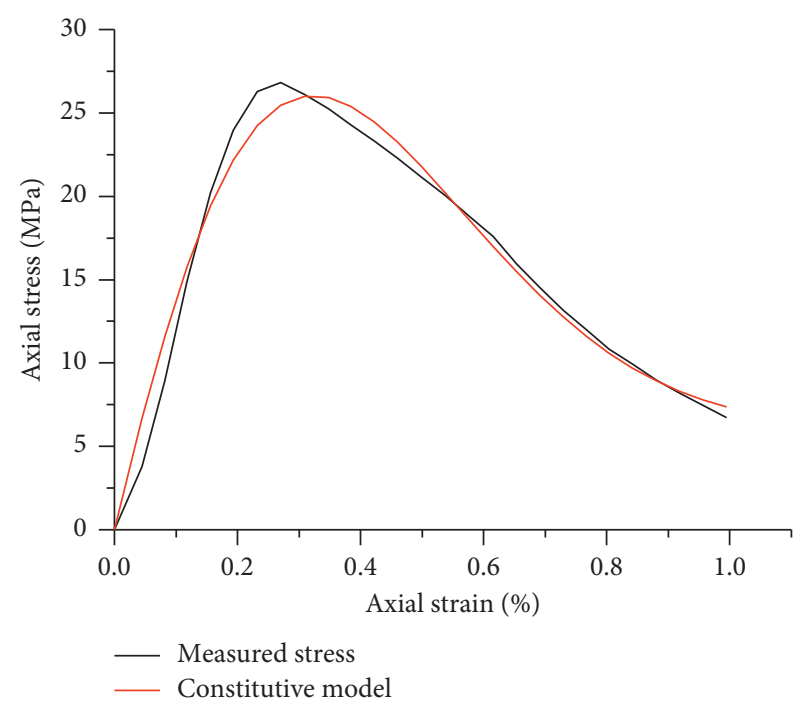

(b)

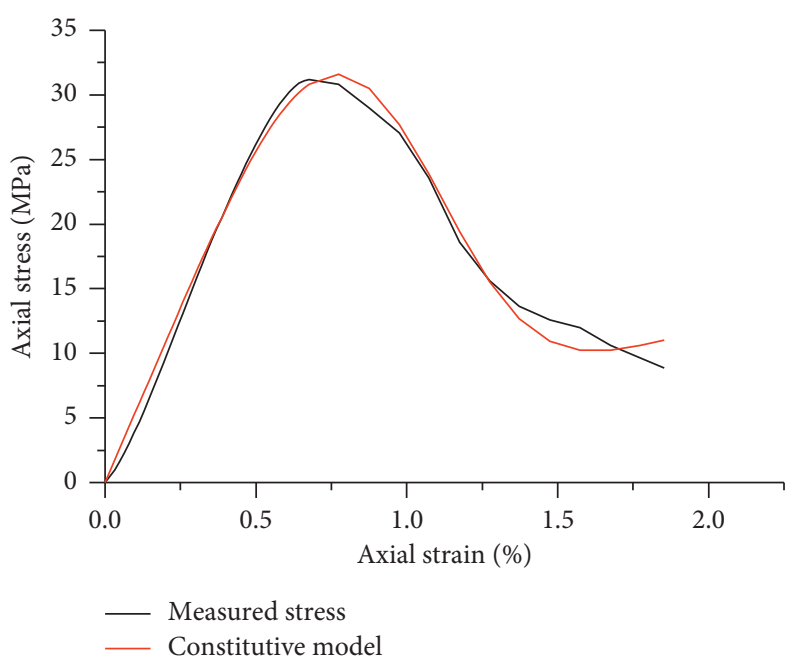

(c)

Figure 8: Comparison between experimental data and theoretical models. (a) Comparison of experimental data and theoretical model for dry shotcrete. (b) Comparison of experimental data and theoretical model for wet shotcrete. (c) Experimental data for WPMS.

Figure 8 illustrates that the statistical damage theoretical model is in good agreement with the experimental results and can better fit the full stress-strain curves of three types of concrete: as concrete can bear some stresses even when microelement damage occurs under compression, a damage coefficient is introduced under compression to establish a damage statistical constitutive model for concrete. The model has few parameters and can elaborate the characteristics of the full stress-strain curve of concrete and thus has engineering reference value. 


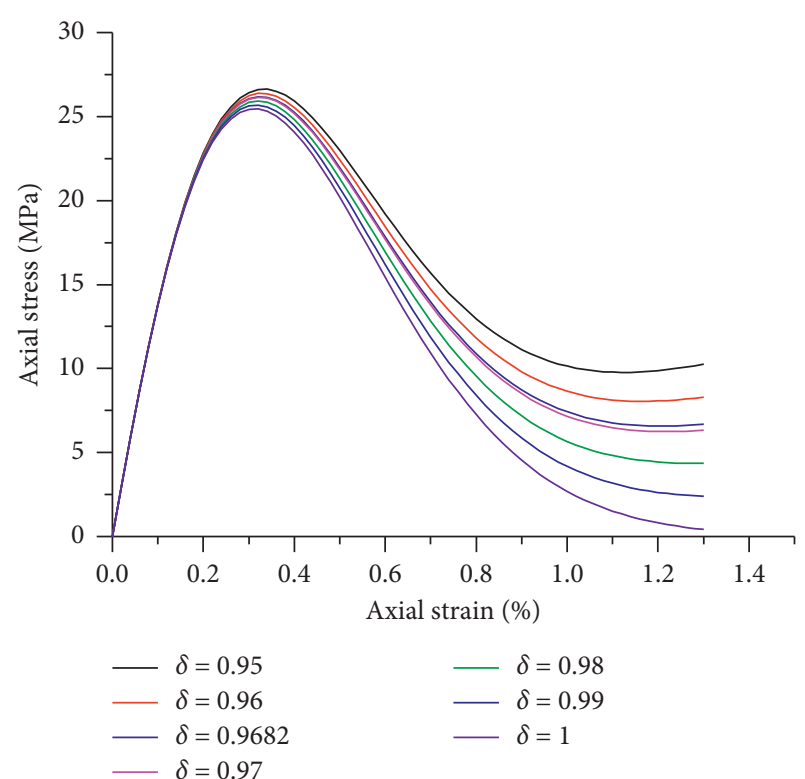

FIGURE 9: Influence of the damage coefficient on the stress-strain curve.

4.3. Sensitivity Analysis: the Damage Coefficient. Based on the parameters determined by test data of wet shotcrete, a series of curves were obtained by changing the damage coefficient and keeping other parameters unchanged (Figure 9).

As shown in Figure 9, the residual strength is zero when the damage coefficient is 1 ; as the damage coefficient $\delta$ decreases, the peak strength of the concrete slightly increases, but the residual strength gradually increases. That also complies with the definition of the damage coefficient. When $\delta$ is 1 , it implies complete damage, and the microelement has no bearing capacity thereafter; when $\delta$ is less than 1 , it denotes incomplete damage, and the microelement can still withstand a certain stress after the onset of damage; the smaller the damage coefficient $\delta$, the greater the residual strength, which evinces material ductility.

The damage coefficients of dry shotcrete and wet shotcrete are similar (Table 5), but the damage coefficient of WPMS is significantly smaller than the former two. This means that the polypropylene macrofibers significantly enhance the material properties of concrete $[22,34,35]$. The study shows that the larger the damage coefficient, the more the ductile and the concrete and the greater its residual strength. Therefore, the ductility of the WPMS has been shown to have been significantly enhanced.

\section{Conclusion}

(1) The mechanical properties of WPMS are better than those of dry shotcrete and wet shotcrete. The ductility of polypropylene macrofiber-reinforced shotcrete is significantly enhanced, and the residual strength is larger. It can still bear load after failure.

(2) The energy absorbed by the early-stage concrete is greater, and the energy absorbed by the WPMS is higher in the later stages of loading. The polypropylene macrofiber-reinforced concrete has a high strength and good ductility at fracture initiation; the large amount of energy released from polypropylene macrofiber-reinforced shotcrete occurs after reaching the peak stress while it occurs at the peak stress for the plain shotcrete. The average energy absorbed by the WPMS is much greater than that of dry and wet shotcrete. This means that WPMS is helpful in preventing the dynamic failure of the sprayed layer from evolving into loss of deformation stability and incipient brittle instability.

(3) Based on the test data pertaining to the three different types of materials and the damage coefficients thereof, the constitutive model parameters of the damage statistics were identified by using the nonlinear least squares method. The fitted results of the unified constitutive model were compared with the experimental data, indicating that only a few model parameters are needed to reflect the characteristics of the full stress-strain curve of concrete.

The research results provide an experimental reference for a better alternative to traditional material mix designs in the form of polypropylene macrofiber-reinforced concrete support.

\section{Data Availability}

The data used to support the findings of this study are available from the corresponding author upon request.

\section{Conflicts of Interest}

The authors declare that they have no conflicts of interest.

\section{Acknowledgments}

The authors thank the technical staff of the relevant organizations and other members of this group for their support and assistance. The study was supported by the Foundation of Young Teachers Scientific Research of Anhui University of Science and Technology (grant no. QN2018110).

\section{References}

[1] R. Moffat, C. Jadue, J. F. Beltran, and R. Herrera, "Experimental evaluation of geosynthetics as reinforcement for shotcrete," Geotextiles and Geomembranes, vol. 45, no. 3, pp. 161-168, 2017.

[2] G. Zhou, S. Li, Y. Ma et al., "Synthesis and properties of a reinforcing dust-cementing material for thin spray-on liners in mine roadways," Advances in Materials Science and Engineering, vol. 2019, Article ID 8486534, , 2019.

[3] F. Ning, Y. Cai, Y. Bai et al., "Effect of expansive agent and internal curing agent on crack resistance of C50 silica fume wet-mix shotcrete," Advances in Mechanical Engineering, vol. 11, no. 1, pp. 1-11, 2019.

[4] Y. Xu, L. Liu, J. Zhang et al., "Experimental study on basic mechanical properties of steel fiber-reinforced siliceous wet 
shotcrete," Advances in Materials Science and Engineering, vol. 2018, Article ID 1637261, , 2018.

[5] F. Aslani and S. Nejadi, "Self-compacting concrete incorporating steel and polypropylene fibers: compressive and tensile strengths, moduli of elasticity and rupture, compressive stress-strain curve, and energy dissipated under compression," Composites Part B: Engineering, vol. 53, pp. 121-133, 2013.

[6] A. Caggiano, S. Gambarelli, E. Martinelli, N. Nisticò, and M. Pepe, "Experimental characterization of the post-cracking response in hybrid steel/polypropylene fiber-reinforced concrete," Construction and Building Materials, vol. 125, pp. 1035-1043, 2016.

[7] Y. Chi, L. Xu, and Y. Zhang, "Experimental study on hybrid fiber-reinforced concrete subjected to uniaxial compression," Journal of Materials in Civil Engineering, vol. 26, no. 2, pp. 211-218, 2014.

[8] H. Cifuentes, F. García, O. Maeso, and F. Medina, "Influence of the properties of polypropylene fibres on the fracture behaviour of low-, normal- and high-strength FRC," Construction and Building Materials, vol. 45, pp. 130-137, 2013.

[9] Y. Bi, Y. Kong, D. Cai et al., "Application of high toughness fibers concrete in deep soft rock roadway," Journal of China Coal Society, vol. 35, no. 12, pp. 1969-1974, 2010.

[10] C.-P. Lu, Y. Liu, N. Zhang, T.-B. Zhao, and H.-Y. Wang, "Insitu and experimental investigations of rockburst precursor and prevention induced by fault slip," International Journal of Rock Mechanics and Mining Sciences, vol. 108, pp. 86-95, 2018.

[11] C.-P. Lu, G.-J. Liu, Y. Liu, and H. Zhang, "Mechanisms of rockburst triggered by slip and fracture of coal-parting-coal structure discontinuities," Rock Mechanics and Rock Engineering, vol. 52, no. 9, pp. 3279-3292, 2019.

[12] C.-P. Lu, G.-J. Liu, Y. Liu, N. Zhang, J.-H. Xue, and L. Zhang, "Microseismic multi-parameter characteristics of rockburst hazard induced by hard roof fall and high stress concentration," International Journal of Rock Mechanics and Mining Sciences, vol. 76, pp. 18-32, 2015.

[13] E. Proverbio, "Evaluation of deterioration in reinforced concrete structures by AE technique," Materials and Corrosion, vol. 62, no. 2, pp. 161-169, 2011.

[14] S. Degala, P. Rizzo, K. Ramanathan, and K. A. Harries, "Acoustic emission monitoring of CFRP reinforced concrete slabs," Construction and Building Materials, vol. 23, no. 5, pp. 2016-2026, 2009.

[15] D. G. Aggelis, "Classification of cracking mode in concrete by acoustic emission parameters," Mechanics Research Communications, vol. 38, no. 3, pp. 153-157, 2011.

[16] D. Soulioti, N. M. Barkoula, A. Paipetis, T. E. Matikas, T. Shiotani, and D. G. Aggelis, "Acoustic emission behavior of steel fibre reinforced concrete under bending," Construction and Building Materials, vol. 23, no. 12, pp. 3532-3536, 2009.

[17] J. Li, J. Huang, J. Niu, and C. Wan, "Mesoscopic study on axial compressive damage of steel fiber reinforced lightweight aggregate concrete," Construction and Building Materials, vol. 196, pp. 14-25, 2019.

[18] M. Aslan, "Investigation of damage mechanism of flax fibre LPET commingled composites by acoustic emission," Composites Part B: Engineering, vol. 54, pp. 289-297, 2013.

[19] J. Geng, Q. Sun, Y. Zhang, L. Cao, and W. Zhang, "Studying the dynamic damage failure of concrete based on acoustic emission," Construction and Building Materials, vol. 149, pp. 9-16, 2017.
[20] T. Shiotani, M. Shigeishi, and M. Ohtsu, "Acoustic emission characteristics of concrete-piles," Construction and Building Materials, vol. 13, no. 1-2, pp. 73-85, 1999.

[21] Y. Wang, S. Chen, L. Zhou et al., "Full curve damage process of polypropylene fiber reinforced mortars under dynamic tensile loading based on acoustic emission technique," Russian Journal of Nondestructive Testing, vol. 54, no. 7, pp. 495-509, 2018.

[22] E. Dong, W. Wang, N. Ma et al., "Analysis of anchor spacetime effect and research of control technology considering creep of surrounding rock," Journal of China Coal Society, vol. 43, no. 5, pp. 1238-1248, 2018.

[23] T. Trcka, J. Lanik, and R. Macku, "Comparing the properties of polypropylene fibers contained in ordinary and lightweight concrete using three-point bending tests with stress concentrator and acoustic emission method," Key Engineering Materials, vol. 592-593, pp. 537-540, 2014.

[24] R. Yu, B. Huang, J. Zhang et al., "Experimental study on splitting tensile strength and acoustic emission characteristics of polypropylene fiber concrete," in Proceedings of the International Conference on Electric Technology, Pasadena, CA, USA, October 2001

[25] X. Niu, Theory and Application of Wet Imitation Steel Fiber Shotcrete Replace Reinforced Shotcrete, Anhui University of Science and Technology, Huainan, Anhui, China, 2017.

[26] H. Liu, Mechanics of Materialspp. 19-24, Higher Education Press, Beijing, China, 5 edition, 2011.

[27] J. Peng, G. Rong, and M. Cai, "Determination of residual strength of rocks by a brittle index," Rock and Soil Mechanics, vol. 36, no. 2, pp. 403-408, 2015.

[28] J. Zuo, Y. Chen, and C. Wang, Destructive Mechanics and Models of Deep Coal-rock Combinations, Science Press, Beijing, China, 2017.

[29] G. Liu, F. Xiao, and Q. Cheng, "Experimental study on acoustic emission characteristics of dry and saturated basalt columnar joints under uniaxial compression and tensile damage," Shock and Vibration, vol. 2019, Article ID 4971695, 12 pages, 2019.

[30] S. C. Angulo, N. V. Silva, D. A. Lange et al., "Probability distributions of mechanical properties of natural aggregates using a simple method," Construction and Building Materials, vol. 233, Article ID 117269, 2020.

[31] M. Zhang, F. Wang, Q. Yang et al., "Statistical damage constitutive model for rocks based on triaxial compression tests," Chinese Journal of Geotechnical Engineering, vol. 35, no. 11, pp. 1965-1971, 2013.

[32] J. F. Zapata, M. Gomez, and H. A. Colorado, "Structureproperty relation and Weibull analysis of calcium aluminate cement pastes," Materials Characterization, vol. 134, pp. 9-17, 2017.

[33] S. Q. Yang, W. Y. Xu, L. D. Wei et al., "Statistical constitutive model for rock damage under uniaxial compression and its experimental study," Journal of Hohai University, vol. 32, no. 2, pp. 200-203, 2004.

[34] W. D. Ni and A. C. Shi, "Numerical study on unloading damage of columnar jointed basalt at baihetan hydropower station," Journal of Yangtze River Scientific Research Institute, vol. 34, no. 10, pp. 85-90, 2017.

[35] L. Chen, W. Zhang, J. Liu et al., "Research on seismic performance of slab-column shear wall structure based on collapse analysis," Building Structure, vol. 48, no. 9, pp. 34-42, 2018. 